\title{
Determinants of Food and Nutrition Security in Côte d'Ivoire: Case of Abobo Baoule a Sub-district of the Ivorian Political Capital in West Africa
}

\section{Yoboue N'da Mireille ${ }^{1 *}$, Assa Rebecca Rachel ${ }^{2}$, N'guessan Anon Franck-Donald ${ }^{3}$ and Kouakou Egnon KV $^{4}$}

${ }^{1}$ UNESCO Chair, Félix Houphouët Boigny University, Abidjan, Côte d'Ivoire

${ }^{2}$ Laboratory of Biotechnology, Agriculture and Valorization of Biological

Resources, UFR Biosciences, Félix Houphouët-Boigny University, Abidjan, Côte

d'Ivoire

${ }^{3}$ National Nutrition Program, Ministry of Health and Public Hygiene, Abidjan, Ivory

Coast, Côte d'Ivoire

${ }^{4}$ Laboratory of Nutrition and Pharmacology, Faculty of Biosciences, University Félix

Houphouet-Boigny, Ivory Coast, Côte d'Ivoire

*Corresponding Author: Yoboue N'da Mireille, UNESCO Chair, Félix Houphouët

Boigny University, Abidjan, Côte d'Ivoire.

DOI: $10.31080 /$ ASNH.2020.05.0815
Received: December 05, 2020

Published: January 21, 2021

(C) All rights are reserved by Yoboue N'da

Mireille., et al.

\begin{abstract}
In Côte d'Ivoire, the food and nutritional situation of households has weakened in recent decades according to the ministries of agriculture and health. Experts propose increased monitoring of the situation to avoid a food crisis, capable of disrupting the socioeconomic stability of the country. In order to contribute to this strategy, a study was carried out. The study aims to analyze the level of food and nutritional security of the populations of Abobo-Baoulé, in the district of Abidjan, in Côte d'Ivoire. Thisstudy is a crosssectional descriptive and analytical that involved a sample of 300 households and 453 children under 5 years old.

The results reveal rates of $23.70 \%$ medium food security, $26.30 \%$ low food security, $24 \%$ very low food security and low dietary diversity. In addition, the children present a poor nutritional state with rates of $5.1 \%$ of acute malnutrition, $12.40 \%$ of chronic malnutrition and $3.7 \%$ of overweight.

These results show that food and nutrition security in the country has not changed, compared to previous work and still remains precarious. This could be justified by inadequacies in the search for the causes, and in the implementation of interventions with households.

To this end, it would be necessary to revise the causal analysis of the food situation and target the most vulnerable households, in order to reduce malnutrition in Abobo-Baoulé's locality.
\end{abstract}

Keywords: Households; Food and Nutritional Security; Eating Habits; Côte d'Ivoire

\section{Introduction}

Food insecurity is defined as the restricted, inadequate or uncertain access of individuals and households to healthy and nutri- tious foods that are personally acceptable in terms of quantity and quality to meet energy needs and lead healthy and productive lives [1]. 
Considered the result of several often complex and intertwined factors, food insecurity is a real development problem in Africa [2].

In West Africa, the acute food and nutrition security crisis of 2008 continues to affect populations, especially the most vulnerable households, which show an erosion of resilience in the face of recurrent shocks and who still need assistance [3].

In Côte d'Ivoire, the survey on the vulnerability of Households in Urban Areas (VAMU) conducted by the Ministry of Agriculture reveals a high rate of $34.6 \%$ of severe food insecurity [4].

According to the National Nutrition Program of Cote d'Ivoire, this situation results in a fragile and worrying nutritional state of $6.5 \%$ of global acute malnutrition [5]. It requires increased surveillance for the prevention of a food crisis and a socio-economic and stable emergence of populations.

Thus, a study was carried out in Abidjan, precisely in the village of Abobo-Baoulé, in order to determine the level of household food and nutritional security. This study aims to determine the level of household food security, analyze household eating habits and analyze the nutritional status of the population.

\section{Materials and Methods}

Material

Study framework

The study took place in the locality of Abobo-Baoulé, a village in the commune of Abobo, located north of the economic capital of Côte d'Ivoire. Abobo baoulé is between $3^{\circ} 58$ 'West Longitude and $5^{\circ} 27^{\prime}$ North Latitude. It is bounded to the north by the Belle-ville district, to the south by the Abobo-Té and Samaké districts, to the east by the municipality of Cocody and to the west by the Kennedy district [6]. It has within it a market interconnected with the large Abidjan market. A community health center is also available within the village for the management of cases of malnutrition. AboboBaoulé was chosen because it is a village located in an urban environment. Indeed, there is a population that has both rural and urban habits [6]. The community was informed through a letter addressed to the chiefdom.

\section{Study population}

This study covers households and children under 5 years old in the village. The interviewee in each household was the head of the household, selected according to the following criteria:
- Inclusion criteria: It was included, heads of household and children under 5 years old residing in the village for at least 12 months before the start of the study, and having agreed to participate in the study after informed consent.

- Non-inclusion criteria: Heads of household and children under 5 years old occasionally residing in the village and those who did not give their consent were not included in the study.

\section{Data collection tools}

Initially, a pilot pre-survey in the village of Biabou was enabled the validation of the questionnaires and the method of analysis.

The data obtained were entered using Excel 2013 software and then exported to SPSS 20 software for analysis.

In order to assess the nutritional status of the population, the weight and height of children under 5 years old were measured. The weight/height and height/age ratio of these children were then calculated.

Methods

Type and period of the study

This investigation is a descriptive and analytical cross-sectional study, based on the collection and analysis of qualitative and quantitative data related to the food security of the inhabitants of Abobo-Baoulé. It took place from December 01, 2018 to January 15, 2019.

\section{Sampling}

The required household sample size was calculated by applying Fisher's formula [7]:

$\mathrm{N}=\mathrm{t}^{2} \times \mathrm{p}(1-\mathrm{p}) / \mathrm{m}^{2}$

$\mathrm{N}=$ required sample size

$t=95 \%$ confidence level (typical value of 1.96 )

$\mathrm{p}=$ estimated prevalence of food insecurity in the area. This estimated prevalence is assumed to be $0.5 \%$ in nutritional surveys when it is not known [7].

$\mathrm{m}=$ margin of error at $5 \%$ (typical value of 0.05 )

Calculation:

$\mathrm{N}=1.96^{2} \times 0.5(1-0.5) / 0.0025$ 
$\mathrm{N}=384.16 \approx 384$

Thus 384 households were expected during the present study.

Using a sampling interval calculated on the basis of the total number of households in the village $(1,256$ according to the local health center), the households were selected by respecting the inclusion criteria without the possibility of replacement. In total, 300 households actually participated in the study.

Regarding the size of the sample of children surveyed, it was also calculated on the basis of Fisher's formula [7].

$\mathrm{N}=\mathrm{t}^{2} \times \mathrm{p}(1-\mathrm{p}) / \mathrm{m}^{2}$

$\mathrm{N}=$ required sample size

$t=95 \%$ confidence level (typical value of 1.96 )

$\mathrm{p}=$ Estimated prevalence of global acute malnutrition in the study area.

According to the results of Amoikon., et al. [8], the prevalence of an area close to that of our study was $7.75 \%$

$\mathrm{m}=$ margin of error at 5\% (typical value of 0.05 )

Calculation:

$\mathrm{N}=1.96^{2} \times 7.75 \%(1-7.75 \%) / 0.0025$

$\mathrm{N}$ (required population) $=421.86 \approx 422$

Fulfilling the inclusion criteria, a total of 453 children participated in the nutritional assessment with the consent of their parents.

\section{Food security assessment method}

The food security assessment was carried out according to the Food And Nutrition Technical Assistance (FANTA) method proposed by FAO [9]. It consisted in sending the head of the household a survey sheet comprising 9 questions relating to the availability, use, accessibility and stability of food in the household. All these questions were asked assuming a recall period of 4 weeks (30 days).

\section{Method for assessing eating habits}

The assessment of eating habits was consisted to determine the diversity of the diet and the frequency of food consumption.
Regarding dietary diversity, the FAO tool was used [9].

In terms of frequency of consumption, it was assessed on the basis of the work of Amoikon., et al. [8].

Thus, the frequency of consumption of foods other than fruits and vegetables, the respondents had to specify the number of days per week when they used to consume the proposed food. For example, if an individual usually consumes rice on Monday, Wednesday, Thursday, and Friday, that would be four times a week.

In order to facilitate the analysis, these frequencies have been grouped by category with reference to the work of Amoikon., et al. [8]. These categories were starchy foods, cereals, tubers, sugar and sweet foods, dairy products, fat and meat-fish and eggs category.

Regarding fruits and vegetables, the number of servings of fruits and vegetables consumed per day was evaluated.

\section{Method for assessing nutritional status}

The assessment of nutritional status was carried out according to the method proposed by WHO and UNICEF [10]. The first step was to measure the child's weight, height and age. Next, determine the weight/height ratio for acute malnutrition and overweight and the height/age ratio for chronic malnutrition. Finally, nutritional status was determined according to the Z-score, weight/height and height/age ratios [11].

\section{Statistical analysis}

The collected quantitative and qualitative data were entered using Excel 2013 software and then exported to SPSS 20 software for analysis. Anthropometric data were entered and analyzed in the ENA for smart 2011 software.

\section{Ethical aspects}

Regarding ethical considerations, municipal authorities in Abobo commune, Abobo-Baoulé health center, and the chiefdom of Abobo-Baoulé village have been informed. The respondents were interviewed after free and informed consent. For ensure confidentiality, anonymity number was assigned to each survey sheet.

\section{Results}

Figure 1 shows the level of food security of Abobo-Baoulé households. In fact, in the study population, $26 \%$ of 300 households sur- 
veyed are food secure. On the other hand, $23.7 \%$ have medium food security, $26.3 \%$ low food security and $24 \%$ very low food security.

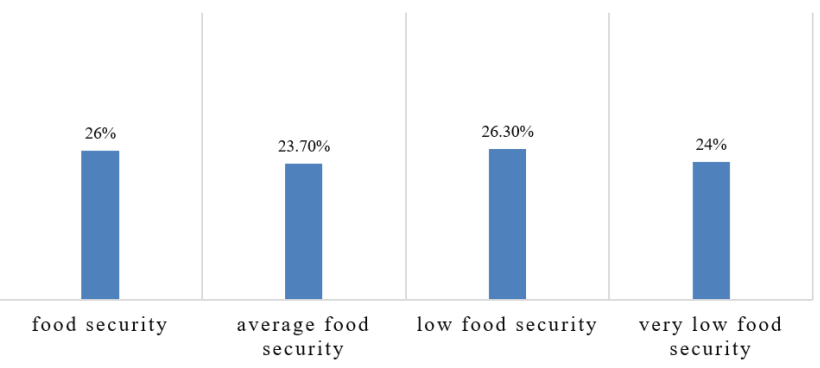

Figure 1: Distribution of the proportions of households surveyed according to their levels of food security.

Regarding the household dietary diversity score (Figure 2), only $5 \%$ of respondents score with a consumption of 6 to 9 food groups. There are $16 \%$ who have an average dietary diversity of 4-5 food groups. The majority of households (79\%) have a low dietary diversity score with 1 to 3 food groups.

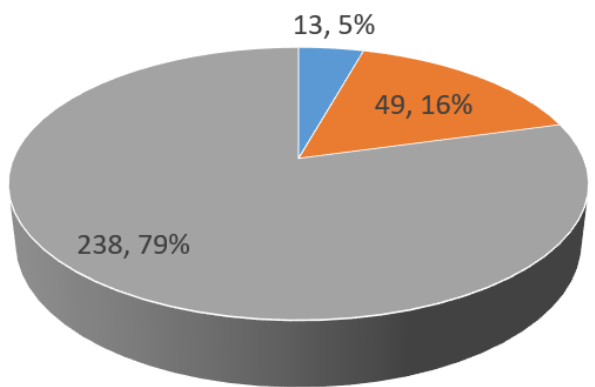

" High diversity $\quad$ - Average diversity $\quad$ - Low diversity

Figure 2: Representation of households surveyed according to their dietary diversity score.

Regarding the frequency of food consumption (Figure 3), cereals are consumed more than five times per week, in $71 \%$ of households. Then, sugar and sugary foods (69\% of households) are the most consumed. $66 \%$ of households consume tubers more than

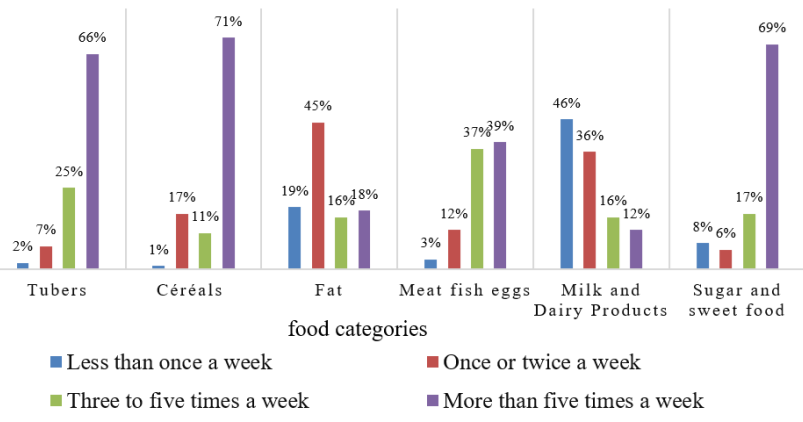

Figure 3: Representation of the frequencies of consumption of the households surveyed of food categories other than fruits and vegetables.

five times a week. Also, animal proteins and vegetable fats (proteinoilseeds, meat, fish and eggs) are consumed at the same frequency in $39 \%$ of households. $18 \%$ and $12 \%$ of households respectively consume more than five times animal fat and dairy products.

The most commonly consumed cereals are broken rice and corn (Figure 4). At the tuber level, consumption is dominated by cassava (Figure 4). Consumption of fruits and vegetables is very low in the study population. In fact, only $8 \%$ of respondents consume at least five servings of fruits and vegetables per day (Figure 5).

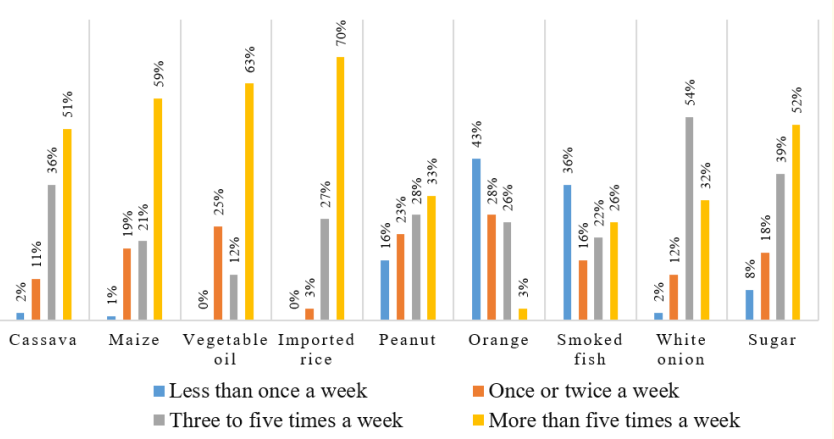

Figure 4: Representation of the consumption frequencies of the households surveyed of the most consumed foods by category. 


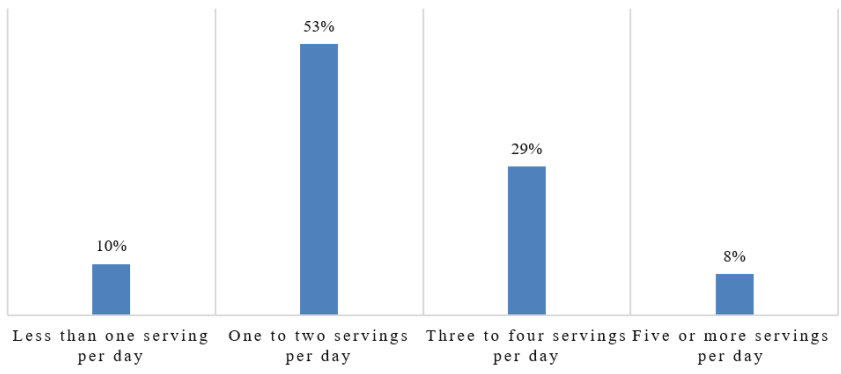

Figure 5: Representation of the proportions of the levels of fruits and vegetables consumption per day of the populations surveyed.

Figure 6 shows the nutritional status of children under 5 years old in the population. There are $3.30 \%$ moderately acutely malnourished children and $1.80 \%$ severely acutely malnourished. Thus, a rate of $5.10 \%$ of global acute malnutrition was recorded in the population. Also, $12.40 \%$ of cases of chronic malnutrition were detected.

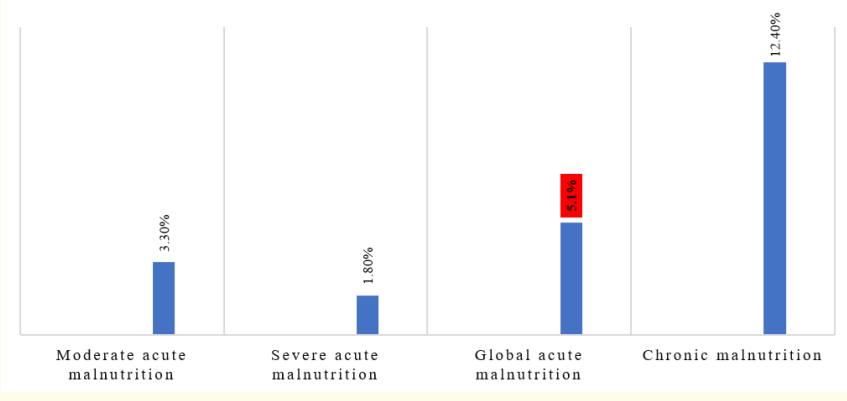

Figure 6: Representation of the levels of nutritional status of children under five years of age surveyed.

\section{Discussion}

This study shows that less than half of the population of AboboBaoulé is food secure. Indeed, only $26 \%$ of respondents are totally food secure and $74 \%$ are food insecure. This prevalence is very close to that of the survey on food vulnerability in urban areas car- ried out in the city of Abidjan, which showed that 29\% of Abidjan households are food secure, $8.8 \%$ slightly food insecure, $27.6 \%$ in moderate food insecurity and $34.6 \%$ in severe food insecurity situation (CILSS and INS, 2013).

When it comes to the dietary diversity score, the majority of households (79\%) have a low dietary diversity score. These results can be superimposed on those of the agricultural season and food vulnerability monitoring study carried out by the Ministry of Agriculture [12].

The combination of the food diversity score and food security results show that the situation is serious and that most households do not have access to a diversified diet. These results are comparable to those of the WFP (2006) in Côte d'Ivoire, which showed that the majority of households did not eat balanced and diverse. Recently, the work of N'guessan., et al. [13] carried out at Félix Houphouët Boigny University in Côte d'Ivoire showed that the majority of respondents do not have a varied eating habit. This could be justified by several factors including the dynamism of the market. Indeed, Benoit Daviron [14] asserted after his work that since the 1990, national and international markets have been a threat to the food security of populations. Bernard Bachelier [15] also maintains that price volatility on the markets is one of the major determinants of the 2008 world food crisis. This author explains that in November 2010, during the world assembly of agriculture ministers, market regulation was one of the key strategies adopted by experts to deal with food insecurity [15].

In the present study, the eating habits are characterized by a high consumption of cereals with $71 \%$ of consumption greater than five times per week. The most widely consumed cereals are broken rice and corn. At the tuber level, consumption is dominated by cassava. These results show that the food profile of the populations is strongly oriented towards certain food products over a whole year. These results are according to the results of Yapi., et al. [16]. These authors noted this eating behavior among respondents.

These eating habits are explained by the fact that frequently consumed foods are highly available and accessible to consumers. In according, the work of Malinowski [17] showed environmental determinism forces humans to choose their foods. Unfortunately, the food choices of the study population often do not take needs into account. Thus, that creates discrepancies between the eating 
habits and the actual nutritional needs of the individual, which can lead to malnutrition.

Indeed, the assessment of the nutritional status of children under five years old in the study area revealed a rate of $5.1 \%$ of acute malnutrition, $12.40 \%$ of chronic malnutrition and $3.7 \%$ of overweight. These results are stackable on those of CILSS (2013) which showed a rate of $5.2 \%$ of acute malnutrition and $10.7 \%$ of chronic malnutrition in Abidjan. The 2016 Multiple Health Indicator Survey (MICS, 2016) in Côte d'Ivoire also found a similar trend, with an acute malnutrition rate of $6.2 \%$ and an overweight rate of $10 \%$. Also, surveys by N'guessan., et al. [13] found similar results in universities in Abidjan with 5.9\% thinness, 9.13\% overweight and $2.2 \%$ obesity. This state of double burden of malnutrition is justified by the high consumption of food with high energy and low nutritional potential, thus creating a dietary imbalance and inevitably malnutrition [18-21].

\section{Conclusion}

In order to analyze the level of food and nutritional security of the populations of Abobo-Baoulé, this study was carried out. It showed that the majority of households are prone to food insecurity. This situation has led to poorly diversified eating habits and a weakening of the state of health of the populations with an alteration in their nutritional status.

These results overlap with those of several previous works carried out in the city of Abidjan and deserve special attention from researchers and policy makers.

Indeed, the most affected households must be targeted. The reasons for this situation must be studied, in order to carry out appropriate and sustainable interventions. This would reduce food vulnerability and malnutrition in the locality of Abobo-Baoulé.

\section{Bibliography}

1. FAO. Report of Committee on World Food Security: Assessment of the World Food Security Situation, Thirty- third Session. in Rome (2007): 11.

2. Abekhti A. "Evolution du concept de la sécurité alimentaire et l'importance de l'intégration du bien-être du citoyen dans les systèmes alimentaires". Researchgate 14.2 (2017): 14251431.
3. CILLS. Concertation régionale sur la situation alimentaire et nutritionnelle au sahel et en Afrique de l'ouest. Newsletter CILSS (2018): 37.

4. CILSS et INS. Enquête sur la vulnérabilité alimentaire en milieu urbain: cas de la ville d'Abidjan rapport final (2013): 57.

5. Programme National de la Nutrition de Cote d'Ivoire. Situation nutritionnelle en Côte d'Ivoire, rapport d'activité (2015): 15.

6. Diabagaté S. "Assainissement et Gestion des ordures ménagères à Abobo : cas d'Abobo-Baoulé". Mémoire de master II №...Université Félix HOUPHOUËT- BOIGNY (2015): 17.

7. Babyak C., et al. "Statistique Canada, Méthodes et pratiques d'enquête". Troisième edition (2003): 415.

8. Amoikon KE., et al. "Habitudes alimentaires liées à la survenue de la maladie hémorroïdaire chez les ivoiriens". European Scientific Journal edition 12 (2016): 36-46.

9. Swindale A., et al. Household Dietary Diversity Score (HDDS) for Measurement of Household Food Access: Indicator GuideFood and Nutrition Technical Assistance III Academy for Educational Development, of Washington's press, D.C. 56.45 (2006): 41-48.

10. UNICEF. Stratégie de lutte contre la malnutrition, rapport de consultance d'expert (2015): 153-157.

11. Programme National de la Nutrition de Cote d'Ivoire. Protocole National de la prise en charge intégrée de la malnutrition (2015): 155.

12. Ministère de l'agriculture et des ressources animales. Enquête de suivi de la saison agricole et de la vulnérabilité alimentaire (2018): 86.

13. N'guessan A F D., et al. "Prospective analysis of the relationship between dietary habits and the occurrence of hemorrhoidal disease in a young ivorians' population". International Journal of Recent Scientific Research 9.10 (2018): 29173-29177.

14. Daviron B. "Une histoire de richesse et de puissance”. Synthèse 1 (2020): 392.

15. Bachelier B. La sécurité alimentaire: un enjeu global, Paris, Fondapol 16 (2012):32. 
16. Yapi A., et al. "Prospective analysis of the relationship between intestinal parasitic infections and the occurrence of hemorrhoidal disease in a young ivoirians' population". World Journal of Advance Healthcare Research 2.6 (2018): 12-15.

17. Malinowski B. "Unethéoriescientifiquedelaculture". Lestextesàl'appui 2 (1968): 157-168.

18. Amoikon KE., et al. "Cultural and socio-economic factors and risk of protein in children from 0 to 59 months, attending the general hospital of bingerville (côte d'ivoire)". International Journal of Current Research 10.6 (2018): 70836-70841.

19. InstitutNationaldelaStatistiqueetICFInternational. Enquêtedémographique et de santé etàindicateurs multiples deCôte d'Ivoire 2015-2016 (2016).

20. Institut national destatistiquede Coted'ivoire. Enquête Approfondie sur la Sécurité Alimentaire des Ménages Ruraux (2009): 1755.

21. PAM. Evaluation approfondie de la sécurité alimentaire des ménages ruraux en Côte d'ivoire (2006): 53-54.

\section{Assets from publication with us}

- Prompt Acknowledgement after receiving the article

- Thorough Double blinded peer review

- Rapid Publication

- Issue of Publication Certificate

- High visibility of your Published work

Website: www.actascientific.com/

Submit Article: www.actascientific.com/submission.php

Email us: editor@actascientific.com

Contact us: +919182824667 